\title{
Models for heterogeneous catalysts: studies at the atomic level
}

\author{
Hans-Joachim Freund ${ }^{1}$
}

Received: 1 April 2016/Accepted: 8 June 2016/Published online: 18 August 2016

(c) The Author(s) 2016. This article is published with open access at Springerlink.com

\begin{abstract}
A systematic approach to model heterogeneous catalyst material and characterization at the atomic level is presented. Two examples are used to illustrate the concepts derived from those studies. They document the problems arising on the way to create such model systems and they also indicate possible solutions. The first example is connected with activation of $\mathrm{CO}_{2}$ at the rim of electron rich $\mathrm{MgO}$ (thin film-supported $\mathrm{Au}$ islands), and the second example aims at the creation of a model system for the Phillips catalyst for ethylene polymerization and, in particular, the creation of a hydroxylated silica support.
\end{abstract}

Keywords Surface science $\cdot$ Model catalysts $\cdot \mathrm{CO}_{2}$ activation $\cdot$ Amorphous silica $\cdot$ Silica films

\section{Introduction ${ }^{1}$}

What do we mean by models for heterogeneous catalysts? Catalysis is a kinetic phenomenon, where a material (the catalyst) changes the rate of a chemical reaction without being part of the products (Ertl et al. 1997; Ertl and Freund 1999; Freund and Pacchioni 2008; Freund 2010; Freund et al. 2014; Pacchioni and Freund 2012). This is Ostwald's definition put forward during the nineteenth century

This contribution is the written, peer-reviewed version of a paper presented by a participant to the Conference "Concepts in catalysis: from heterogeneous to homogeneous and enzymatic catalysis" held at Accademia dei Lincei in Rome on February 25-26, 2016.

Hans-Joachim Freund

freund@fhi-berlin.mpg.de

1 Fritz-Haber-Institut der Max-Planck-Gesellschaft, Faradayweg 4-6, 14195 Berlin, Germany
(Ostwald 1923). Most frequently in catalytic literature we encounter "micro-kinetic models" which describe the complex system of elementary reaction and transport steps by a limited, ideally minimum set of rate equations (Marin and Yablonsky 2011). This important aspect is not subject of the present article.

Here we focus on models for the catalytic material. Catalysis may occur under various circumstances: When it occurs at the interface between a solid and a gas or liquid phase we call it heterogeneous catalysis, when it occurs in the liquid phase we call it homogeneous catalysis and when it occurs under the action of an enzyme, which is often a big biologically relevant molecule in the liquid phase we call it enzymatic catalysis. Since the catalyst is not part of the products we really need to look at the material as it performs its action. This is an experimental challenge that has, so far, not been fully met. Since a discovery of a catalytic material has often been based on serendipity, and its optimization on trial and error, it may not be trivial to identify the most important ingredients, even without consideration of the reaction-induced changes. One approach to overcome this problem is to use a systematic model approach (Freund et al. 2014; Marin and Yablonsky 2011)! Take heterogeneous catalysis, which is the topic of this paper, as an example: a reaction between two gaseous components proceeds at the surface of a material containing several components. To identify the active part of the material we need to be able to study a very small amount of starting material and of products at the surface of the complex material, and we need to be simultaneously able to differentiate the surface of the material from its bulk. This requires the development of specific, surface sensitive

\footnotetext{
1 The introduction is reproduced to a large part from Sauer and Freund (2015).
} 
techniques and, to isolate the action of the various material components, a systematic variation in the complexity of the studied material (Freund et al. 2011). This variation has to proceed from the most simple to the more complex, and not vice versa. Only by adding complexity will we be able to finally approach the final real system. In this sense, we set up model systems in catalysis, which may be characterized at the atomic level. There are several levels of models in catalysis, which we try to show as a flow chart in Fig. 1.

We note that progress in the spirit of understanding phenomena at the atomic level will only be achieved by experiment and theory going hand-in-hand. We clearly move, as outlined above from the simple to the complex, and not vice versa, which is important. The bottom of the chart refers to clusters in the gas phase in different charge states. Through a comparison or better a combination between experiment and theory it is possible to unravel details of the reactions taking place in such systems. It has, indeed, been possible to see catalytic reactions, characterized by turnover, on those materials, and this is a first step_The "Ultimate Single Site Catalysis" (Böhme and Schwarz 2005). The small window indicates, that systems at this level of complexity have been investigated in UHV/ ambient molecule level in gas phase and/or in interaction with a gas phase/crossed beams. However, the distance in complexity of the isolated cluster level with respect to supported clusters is far, and the size of clusters, possible to study, has, until now, been limited, although steadily increasing. Having said this, still very useful and unique information on details of reaction mechanisms may be unraveled. At the next level in the chart (Fig. 1), single crystal and well-ordered thin film surfaces have been used successfully in the past to start to understand fundamental phenomena at surfaces. This culminated in the Nobel Prize for Gerhard Ertl in 2007 (Ertl 2007, 2008). Given the enormous success of those studies, the valid question that has been asked is: What comes next? In fact, not too long ago, people have argued: Surface science is dead!! We believe it is clear from what we argued so far that this statement is definitely wrong, if one is interested in unraveling the details of catalytic reactions. But not only in this respect! Single crystal metal studies lack important ingredients of real catalysts: One is the finite size of the metal particles, typically used in the catalyst, and, second, the oxide-metal interface realized by the fact that dispersed metals are typically supported on oxides, which, according to all reports so far, is of enormous importance for the reactions, their activity and selectivity, observed. Not to speak of the addition of modifiers such as poisons or promoters. So we certainly have to move to higher levels of

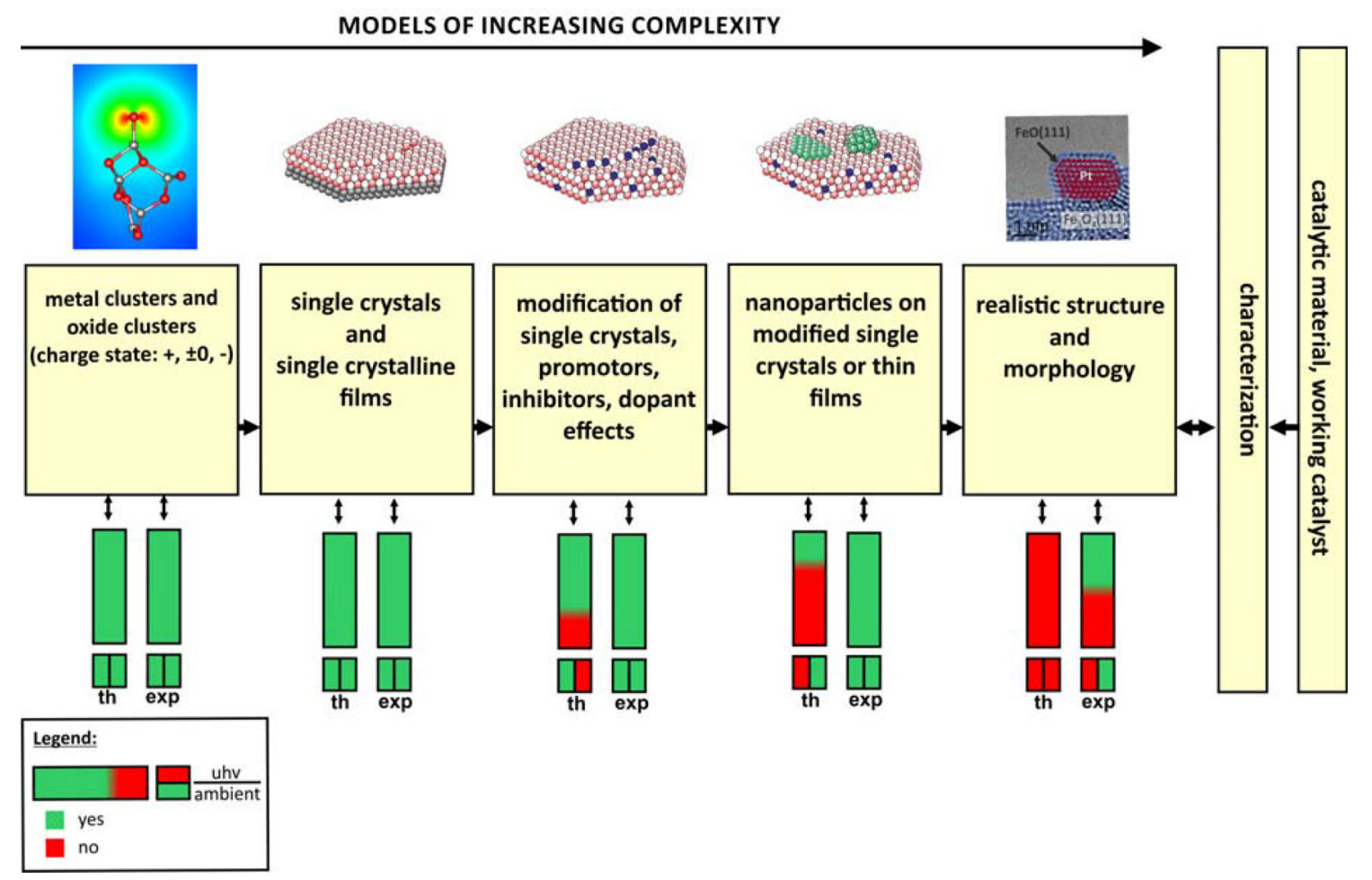

Fig. 1 Schematic and pictorial representation of model systems as a function of increasing complexity to capture the essential features of a working catalyst. Each level is evaluated with respect to experiment and theory and with respect to progress that has been made to achieve a proper representation/description of each level: green: yes, achieved; red: no, not achieved. In addition, it is indicated whether studies have been performed under UHV and under ambient condition (Sauer and Freund 2015) (color figure online) 
model studies as shown in Fig. 1 before we will have a chance to reach a level, which may be directly compared and connected to situations encountered on real catalytic material. This is the point where the two arrows bottom up and top down meet. Through the interplay between experiment and theory, those additional ingredients, indeed, have been identified as essential, and it is the task of researchers in the field, both from theory and experiment, to work together to bring the field forward along the complexity axis shown in Fig. 1. Next to the various levels of complexity, the partially green and red bars indicate how far theory and experiment have come in an effort to describe systems at those levels of complexity properly. Also, it is important to indicate whether studies have been possible under UHV conditions and in addition comparison has been made to in situ studies under ambient conditions. This is indicated by the little window.

I will try to exemplify the approach of experimental and computational model systems by choosing two examples, which the author and his group have worked on, using a variety of experimental and, in collaboration with other groups, theoretical techniques. The examples are basically taken from heterogeneous catalysis. However, it is important to try to unify approaches, a goal that a cluster of excellence in Berlin between the three Berlin Universities and two MaxPlanck Institutes in the Berlin area try to tackle.

Since the complex structure of real, supported metal catalysts often hampers the attempt to connect macroscopic effects with the microscopic processes taking place on the surface, an increasing number of model studies have been conducted so far to tackle these questions. For studies of that kind planar substrates, instead of the technically used porous materials, are needed to take full advantage of modern surface spectroscopic and microscopic techniques (Bäumer and Freund 1999).

Vapor deposition of metals (Campbell 1997; Freund 1997; Bäumer et al. 1997) or deposition of metal clusters from the gas phase (Heiz et al. 1997) under UHV conditions have been preferred in experiments keyed to more fundamental questions about the correlation between structure and properties of small metal particles.

In these cases, well-ordered substrates are desirable, just to know where the atoms are. The most straightforward choice in this context are single crystal samples of course. Studies of bulk oxides, however, can be connected with severe experimental problems. Their insulating character can restrict or even prevent electron and ion spectroscopic, as well as low-energy electron diffraction (LEED) and scanning tunneling microscopic (STM) measurements. Only in cases where the oxide can be made sufficiently bulk conducting (e.g., $\mathrm{TiO}_{2}$ ), this limitation may not apply (Diebold et al. 1995; Persaud and Madey 1997). Other difficulties encountered are related to sample mounting and cleaning (adjustment of surface stoichiometry) or arise from the poor thermal conductivity associated with oxide materials.

In this context, ultra-thin oxide films grown on a metallic substrate are an excellent alternative to circumvent all these problems (Freund 1997; Bäumer et al. 1997; Goodman 1994, 1995). It has been shown that even films with a thickness of just a few Angstroms can exhibit physical properties characteristic of the bulk material (Freund 1995). The traditional method to prepare such films is the oxidation of the native metal (Freund 1995) or an alloy (Jaeger et al. 1991; Libuda et al. 1994; Bardi et al. 1992; Becker et al. 1998), although this often results in amorphous or polycrystalline overlayers [e.g., Al oxide on Al (Chen et al. 1987; Belton and Schmieg 1988a, b; Chen et al. 1992), or Si oxide on Si (Rochet et al. 1986; Pantelides et al. 1978)] or films with a rather high defect density. This is due to the large mismatch which usually exists between the metal and the oxide lattice [e.g., $\mathrm{NiO}(100) / \mathrm{Ni}(100)$ (Bäumer et al. 1991)]. There are a few examples where well-ordered crystalline films can be obtained in this way [e.g., $\mathrm{Cr}_{2} \mathrm{O}_{3}$ (111) on $\mathrm{Cr}(110)$ (Kuhlenbeck et al. 1992; Rohr et al. 1997a, b) or $\mathrm{Al}_{2} \mathrm{O}_{3}$ on $\mathrm{NiAl}(110)$ (Jaeger et al. 1991; Libuda et al. 1994) and $\mathrm{Ni}_{3} \mathrm{Al}(111)$ (Bardi et al. 1992; Becker et al. 1998)].

Therefore, other routes have been proposed. Goodman et al., for example, extensively explored preparation techniques based on the evaporation of a metal (or non-metal) onto a host crystal, mostly a refractory metal, in an ambient oxygen atmosphere (Goodman 1994, 1995, 1996). This approach allows one to vary the oxide film thickness, and explore whether the oxide film-metal support interface influences the properties of the supported particles. In fact, the oxide film metal interface may be used to control charge transfer from the interface to the supported metal particle.

\section{Examples}

\subsection{Supported metal particles}

After Masatake Haruta discovered (Haruta et al. 1993), that small Au particles, supported on a reducible oxide support $\mathrm{CO}$ oxidation at temperatures lower than room temperature researchers started to wonder about the reasons. Again, the late Wayne Goodman has taken up the problem and conducted the first model studies on supported $\mathrm{Au}$ particles (Chen and Goodman 2008). He used a $\mathrm{TiO}_{2}$ (110) single crystal as model support after reducing the bulk by annealoxidation treatments to render it conducting. His studies revealed, that particles become active in $\mathrm{CO}$ oxidation when its diameter approaches a value below $3 \mathrm{~nm}$. In 
addition, the particles exhibited an unusual morphology: they resembled rafts of finite size and a thickness of only one or two layers. This morphology was later also found via aberration-corrected TEM on real powder-based CO oxidation catalysts (Rashkeev et al. 2007; Herzing et al. 2008). The question is, what causes this peculiar morphology to sustain, as metals typically form 3-dimensional particles, driven by the relative magnitude of oxide and metal surface energies. This discussion will be used to shed light on this question.

In 2006 Pacchioni and Landman published a landmark paper (Ricci et al. 2006), the result of which is depicted in Fig. 2.

Density functional calculations of $\mathrm{Au}_{20}$ on either a thick slab of $\mathrm{MgO}(100)$, representing the bulk material, or on a two layer $\mathrm{MgO}(100)$ film on $\mathrm{Mo}(100)$ clearly indicated above, the three-dimensional tetrahedral structure of $\mathrm{Au}_{20}$ (Li et al. 2003) is conserved on bulk MgO. On the contrary, on the thin film the morphology changes drastically: $\mathrm{Au}_{20}$ forms a one-layer raft. The reason is the charge transfer from the $\mathrm{MgO} / \mathrm{Mo}$ interface to the electronegative $\mathrm{Au}$, which may be maximized by bringing the Au atoms as close as possible to the interface, thus leading to raft formation. The lesson to be learned from this calculation, if it could be experimentally verified, is twofold: (1) Charge transfer influences the morphology of Au nano-particles, (2) There has to be a source for this charge transfer within the support, and the energetics have to be just right, i.e., the relative energy needed to remove an electron from the source and the energy gained by attaching it to the metal. The predicted change of the Au nano-particles with respect to morphology was proven by Sterrer et al. in 2007 experimentally (Sterrer et al. 2007) by comparing STM images of $\mathrm{Au}$ deposits on an ultrathin and a thicker $\mathrm{MgO}$ that, as expected in the light of what has been argued

film. Additional studies on Au clusters containing a varying number of atoms have been investigated in detail to characterize the nature of the charge transfer in more detail. Using the STM as a spectrometer, we have determined the symmetry and electron distribution in the highest occupied states as well as in the lowest un-occupied states, which consequently allows you to-so to speak-count the number of electrons (Lin et al. 2009). Furthermore, the localization of the additional electrons within the nanoparticle was imaged as shown in Fig. 3 (Lin et al. 2010a), clearly indicating that they are localized at the rim of the nano-particle, thus provoking the question, whether this is might also be the place where reaction would take place?

In a series of studies we have addressed this question, realizing that the question is difficult to answer experimentally, as so far only clear evidence from model calculations have been presented indicating a particular reactivity of the metal/oxide interface at the rim of the particle, while all experimental evidence was indirect, i.e., there have been no images of molecules in a reacting system at the rim of particles.

First attempts to image molecules at the rim where undertaken by Lin et al. (2010b) using $\mathrm{CO}$ as a probe molecule. Using inelastic electron tunneling spectroscopy (Langan and Hansma 1975; Stipe et al. 1998), as introduced by Ho and coworkers into UHV surface science, Lin et al. were able to show that a low lying $\mathrm{CO}$ vibration frequency, in particular the frustrated rotation at about $45 \mathrm{meV}$ excitation energy can only be found at the rim of an artificially shaped nano-particle similar to those in Fig. 3. Figure 4 collects images of Au islands after exposure to CO. The left panel represents the morphology in a constant current image. The two other panels contain images recorded at a loss- and a gain-energy of $45 \mathrm{meV}$ of the same island after exposure to $\mathrm{CO}$.

Fig. 2 Relaxed atomic configurations of isolated $\mathrm{Au}_{n}$ cluster isomers (a-d) and upon adsorption on the $\mathrm{MgO} /$ $\mathrm{Mo}(100)(\mathbf{e}-\mathbf{f}) \cdot \mathbf{a} \mathrm{Au}_{8} 3 \mathrm{D}$ cluster isomer. b $\mathrm{Au}_{8}$ planar cluster isomer. c $\mathrm{Au}_{16}$ spherical-like cluster isomer. d $\mathrm{Au}_{16}$ planar cluster isomer. e, $\mathbf{f} \mathrm{Au}_{20}$ pyramidal (fcc) and planar cluster isomers, respectively. Yellow, green, red, and dark blue spheres correspond to $\mathrm{Au}$, $\mathrm{Mg}, \mathrm{O}$, and Mo atoms, respectively (Ricci et al. 2006) (color figure online)

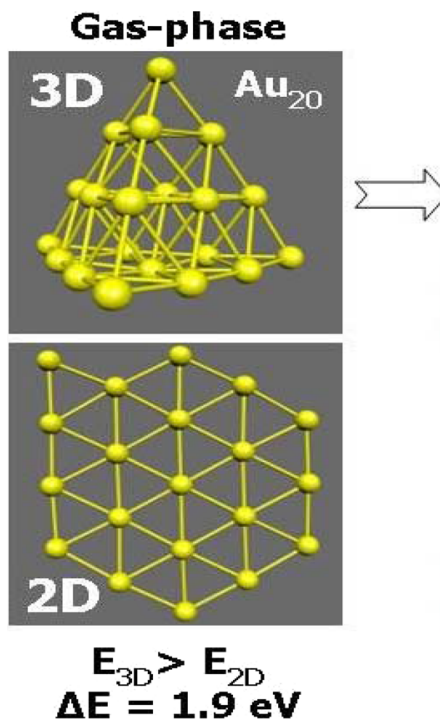

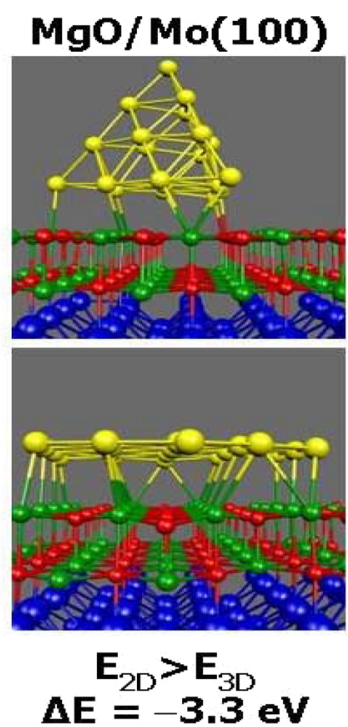



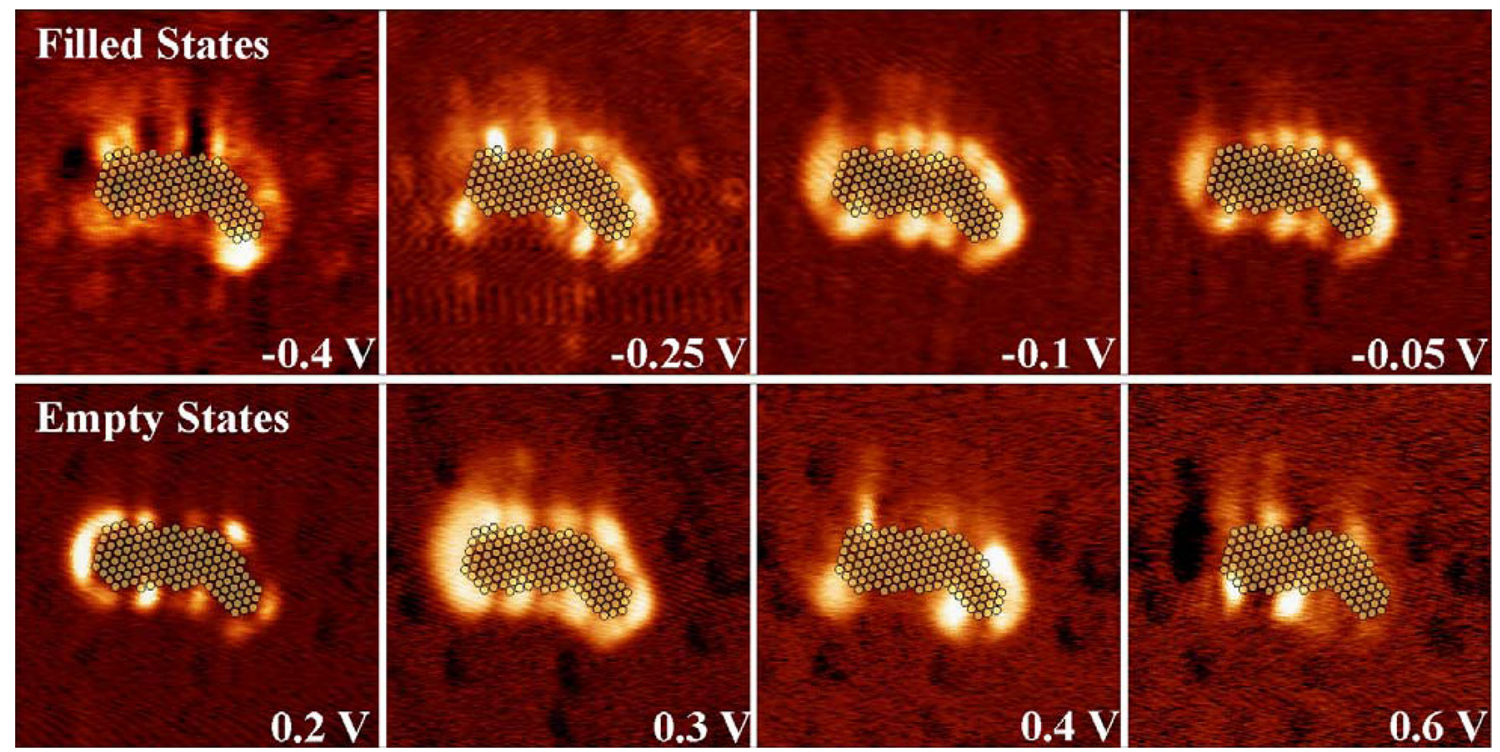

Fig. 3 Filled and empty state $\mathrm{d} I / \mathrm{d} V$ maps of the Au island shown in Fig. $1 \mathrm{~b}$. High $\mathrm{d} I / \mathrm{d} V$ intensity is only observed along the island edges while the center remains dark at all bias voltages. An atomic model of the island is overlaid (Lin et al. 2010a)

Fig. 4 left panel STM topographic image; middle and right panel corresponding second-derivative maps taken at the indicated energies of a planar Au island saturated with $\mathrm{CO}$

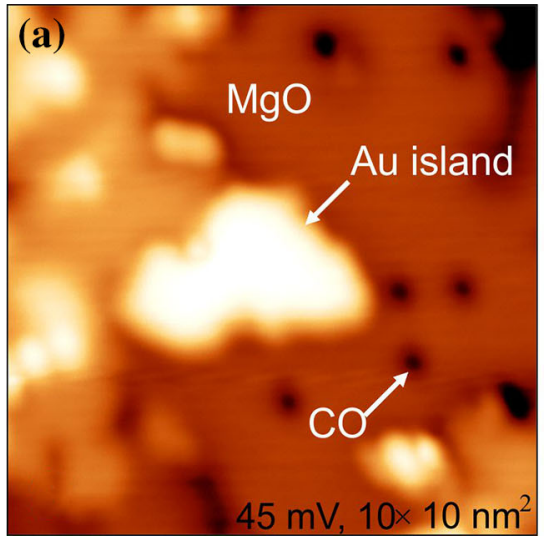

The images reveal the localization of the molecules at the rim of the particle but they do not provide a direct image of the adsorbed molecules, which is the next challenge we will tackle. Perhaps a larger molecule, which is less mobile than $\mathrm{CO}$, could be used to allow for imaging of individual molecule at the rim. Stiehler et al. (2015) used isophorone in such an attempt and it was successful: Fig. 5 collects STM images taken of the identical Au particle with (left) and without (right) the molecules adsorbed at the rim. This was only possible, because isophorone (structure in the inset and IR spectrum taken of the system identifying isophorone by its vibrational spectrum) is weakly adsorbed, and may be manipulated with the STM tip, such that after taking the images with the adsorbed molecules, those were removed and the image of the naked particle was recorded. This system provided another interesting option, as it allowed us to record the quantum well states of the nanoparticles with and without the adsorbed molecules.
Quantum well states arise from the finite size of the object similar to the well-known particle in-a-box problem solved in undergraduate courses of physical chemistry. The quantum well states as measured through scanning tunneling spectroscopy are shown as spectra (blue and red) taken at two positions within the particle, and, in addition, the conductance maps of the system are shown, clearly indicating the nature of the states involved.

The states shift to lower energy as the molecules are adsorbed and also the separation of the quantum well states is altered. In fact, the states are closer spaced for the system with adsorbed molecules as compared with the naked particle, indicating that the potential well walls are modified in such a way that it effectively gets wider, due to the possibility of the wave-functions to spill out of the $\mathrm{Au}$ particle. The effect is similar to the situation encountered for a particle in-a-box with a wider potential well. Details have been analyzed in Stiehler et al. (2016). This 

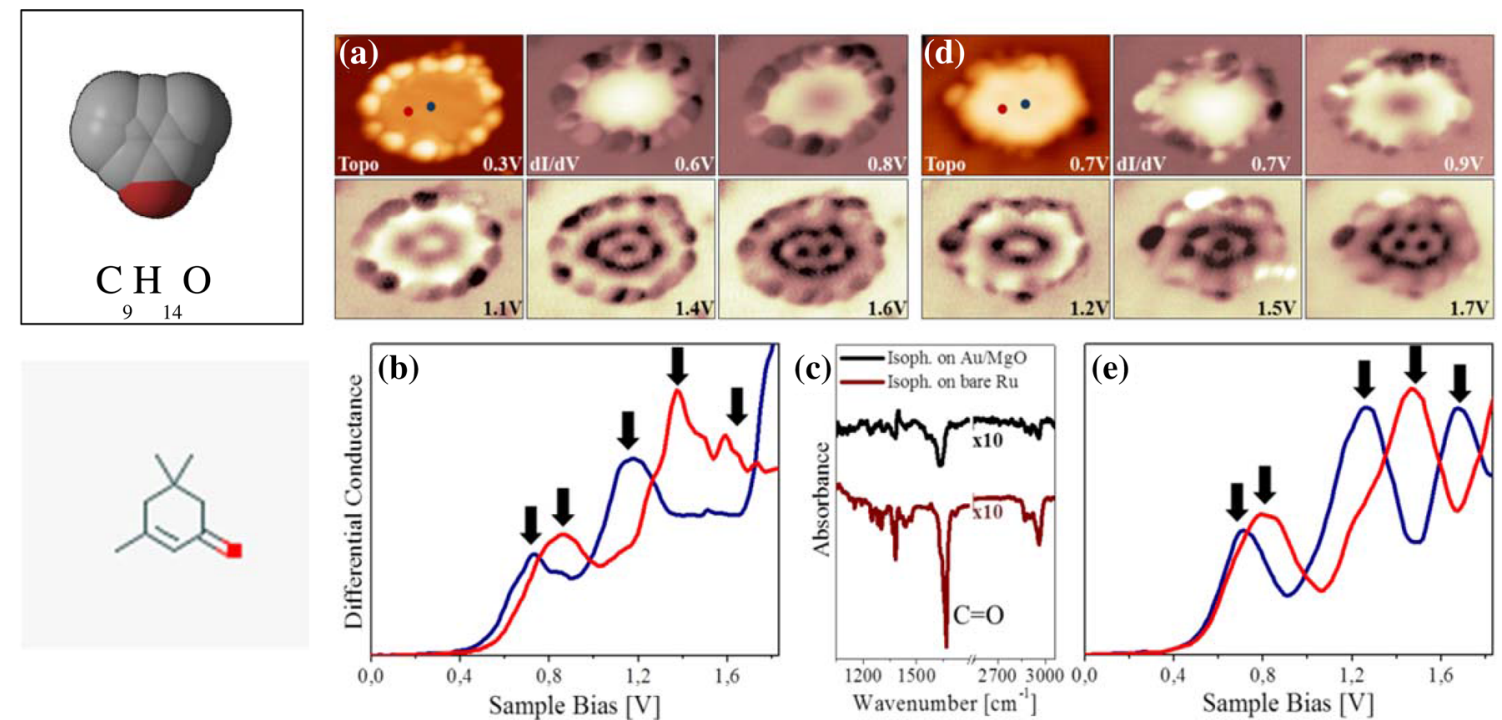

Fig. 5 Topographic and $\mathrm{d} I / \mathrm{d} V$ maps of an $A u$ island (a) with and (d) without isophorone molecules (left panels) bound to its perimeter $\left(11 \times 8 \mathrm{~nm}^{2}, 70 \mathrm{pA}\right)$. b and $\mathbf{e}$ associated conductance spectra taken in the center (blue) and the left part of the island (red) as indicated in (a) and (d). Gaussian fitting revealed five QWSs that are marked by

arrows. Their bias positions match the ones used for $\mathrm{d} / / \mathrm{d} V$ imaging in (a) and (d). c Infrared absorption spectra of isophorone adsorbed on $\mathrm{Au} / \mathrm{MgO}$ (black) and $\mathrm{Ru}(0001)$ (gray). Similar vibrational modes are resolved in both cases, indicating that the molecule adsorbs associatively on the two surfaces (Stiehler et al. 2015) (color figure online)

Fig. 6 Calculated structures of a $\mathrm{CO}_{2}^{-} \cdot \mathrm{CO}_{2}$ dimer and intermolecular arrangement of $\mathrm{CO}_{2}$ molecules in solid $\mathrm{CO}_{2}$ [Adapted from Rossi and Jordan (1979)] (Freund and Roberts 1996)

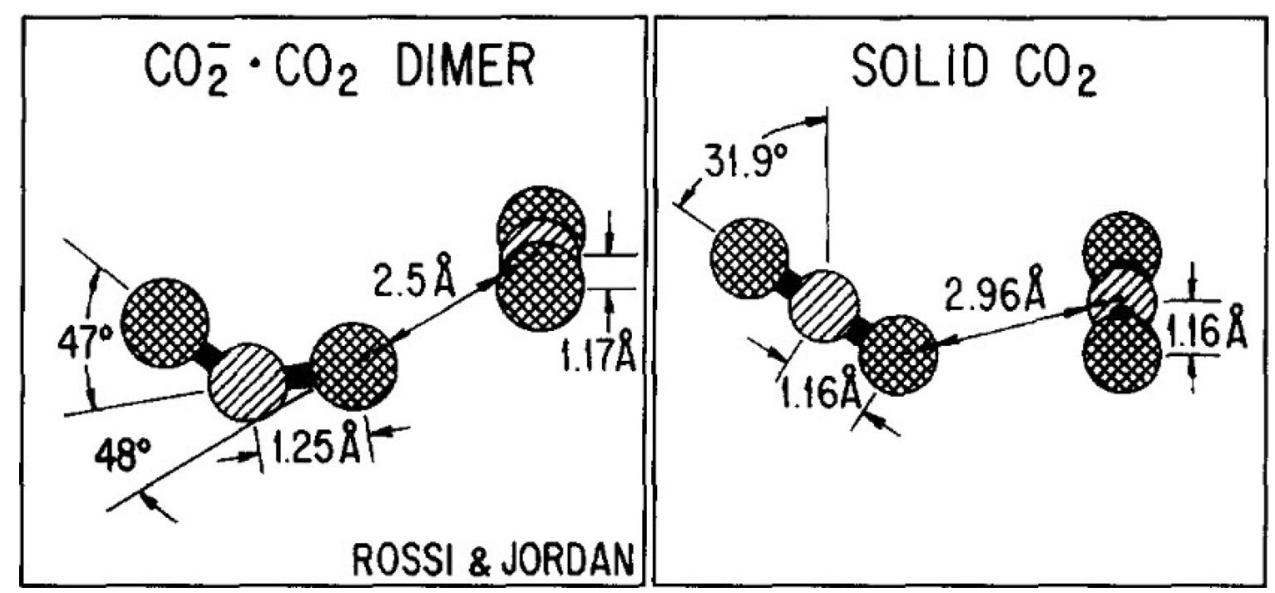

knowledge may now be used to proceed to a situation where molecules at the rim are actually involved in a chemical reaction. Here we combine the above discussed ability of the Au particles to accumulate negative charge and consider a reaction of carbondioxide (Freund and Roberts 1996; Solymosi 1991). To transfer an electron to an isolated $\mathrm{CO}_{2}$ molecule affords $0.6 \mathrm{eV}$ and is thermodynamically unfavorable (Compton et al. 1975). However, a $\mathrm{CO}_{2}$-dimer has a negative electron-affinity $(0.9 \mathrm{eV})$, as has been shown through electron attachment experiments in molecular beams and corroborated by calculations already decades ago (Pacansky et al. 1975; Stamatovic et al. 1985; Quitevis and Herschbach 1989). The structure of such a dimer is plotted in Fig. 6 (Rossi and Jordan 1979) in comparison to the local structure found in solid $\mathrm{CO}_{2}$. Therefore, electron transfer to a dimer, which might be encountered at a surface at sufficiently high coverage, should be thermodynamically favorable.

On this basis, we propose the following scenario (Calaza et al. 2015; O'Brian et al. 2015): the Au nano-particles on a thin $\mathrm{MgO}(100)$ film are negatively charged and may be used as a source to trigger electron transfer to $\mathrm{CO}_{2}$ dimers possibly inducing the formation of an oxalate species, which is nothing but a $\mathrm{CO}_{2}$-dimer-anion with an extra electron transferred, concomitantly to forming a carboncarbon bond to $\mathrm{C}_{2} \mathrm{O}_{4}{ }^{2-}$. Of course, since the Au particles, according to the paper by Pacchioni and Landman (Ricci et al. 2006), alluded to above, only accumulate negative 


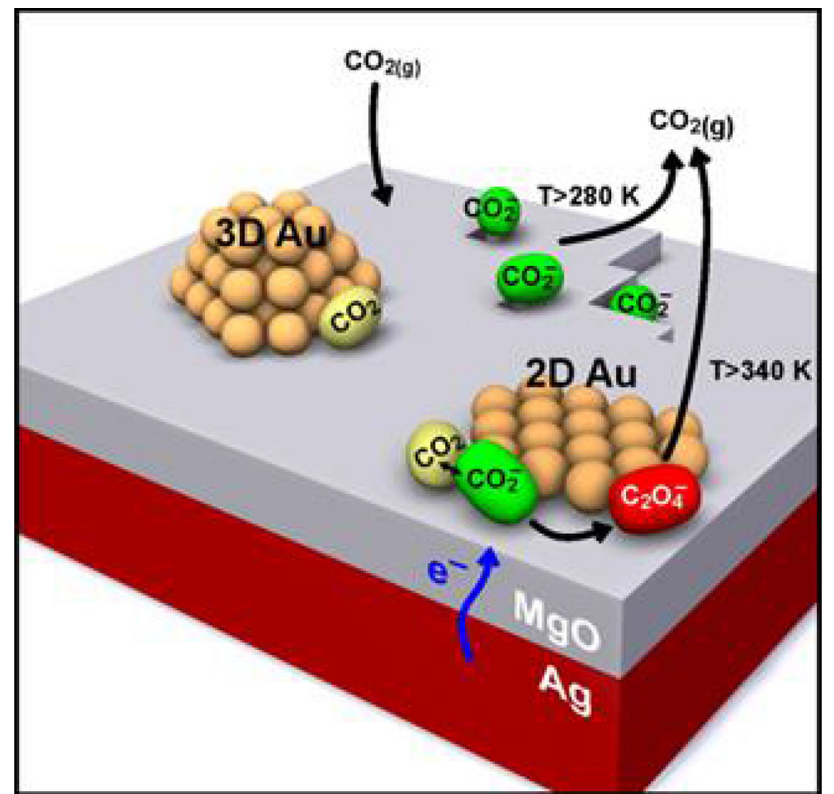

Fig. 7 Schematic showing the individual steps of oxalate formation upon chemisorption of $\mathrm{CO}_{2}$ on the rim of 2D $\mathrm{Au}$ islands on thin $\mathrm{MgO}(001) / \mathrm{Ag}(001)$ films. (Calaza et al. 2015) Carboxylate species (green) are formed both on defect sites of the $\mathrm{MgO}$ film and on the rim of the $2 \mathrm{D} \mathrm{Au}$ islands by electron transfer. Only on the latter, additional $\mathrm{CO} 2$ (yellow) is able to solvate the carboxylate species yielding a $\left(\mathrm{CO}_{2}\right)_{2}$-dimer ion, which, after an additional electron transfer, results in adsorbed oxalate $\mathrm{C}_{2} \mathrm{O}_{42^{-}}$(red). This reaction does not occur on 3D Au particles (O'Brian et al. 2015) (color figure online)

charge in the raft-like flat geometry, it is conceivable, that upon heating, as we increase the mobility of Au atoms on the oxide, three-dimensional Au nano-particles are formed, and electron transfer to the $\mathrm{Au}$ nano particle becomes unfavorable, the reaction is shut off. This scenario is depicted schematically in Fig. 7. Here individual $\mathrm{CO}_{2}$-anions are also shown, formed at defect of the $\mathrm{MgO}$ film. The latter is quantitatively and qualitatively consistent with studies before through EPR titration of oxygen anions and IR measurements on $\mathrm{CO}_{2}$ on other oxide films (Sterrer et al. 2006; Seiferth et al. 1999). However, at those defects, only a single electron transfer may be achieved.
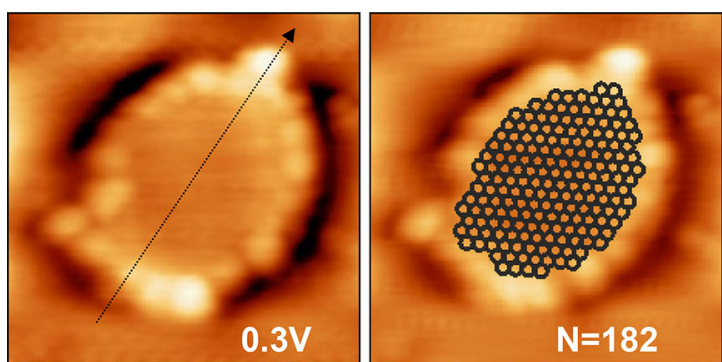

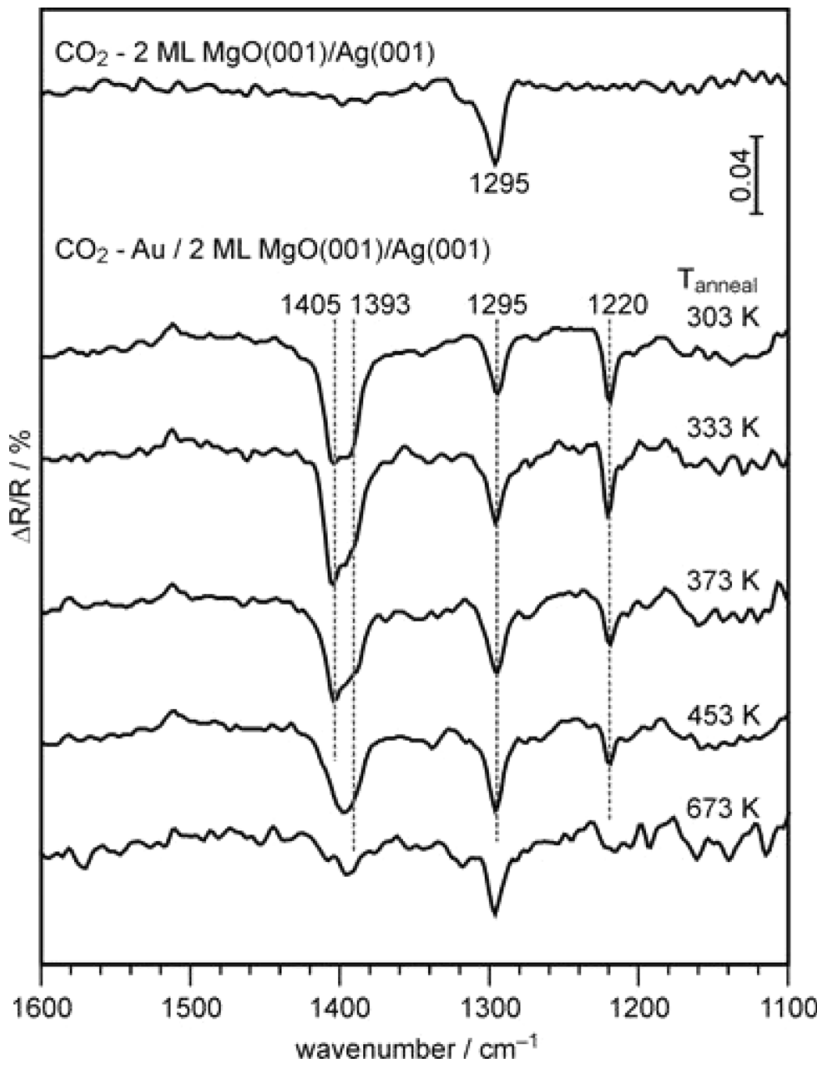

Fig. 9 IRA spectra of bare (top) and Au-loaded $2 \mathrm{ML} \mathrm{MgO}(001) /$ $\mathrm{Ag}(001)$ samples recorded after a saturation dose of $\mathrm{CO}_{2}$ at $223 \mathrm{~K}$. $\mathrm{Au}$ was deposited at $100 \mathrm{~K}$ and the samples subsequently annealed to the indicated temperature prior to $\mathrm{CO}_{2}$ adsorption (O'Brian et al. 2015)

This is, in fact what is experimentally observed. Here we present part of the experimental evidence and refer to the published literature for details. Figure 8 shows STM images of a raft-like $\mathrm{Au}$ anno-particle after exposition to $\mathrm{CO}_{2}$. Clearly, molecular protrusions are observed at the rim (Calaza et al. 2015). Infrared spectra, taken as ensembleaveraging data, are also plotted as a function of temperature. The top trace shows the clean $\mathrm{MgO}$ film after exposure to $\mathrm{CO}_{2}$. The band at $1295 \mathrm{~cm}^{-1}$ is due to carboxylate $\left(\mathrm{CO}_{2}{ }^{-}\right)$formed at defects. This was verified through isotopic labeling experiments (Calaza et al. 2015). The second
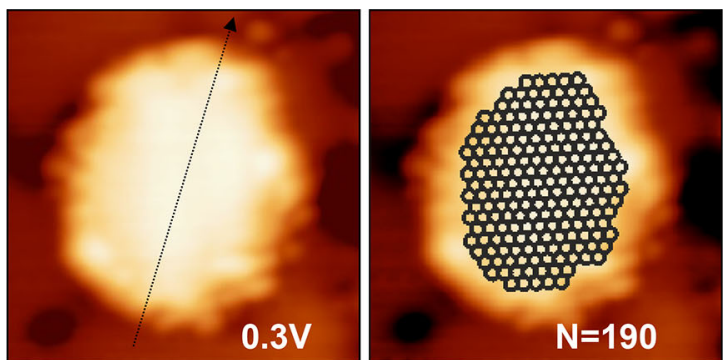

Fig. 8 STM topological images of an Au particle with isophorone molecules at the rim (left panel), the Au island is schematically shown as a model. The right hand panels show a similarly shaped Au particle without adsorbed isophorone particle (Stiehler et al. 2015; Calaza et al. 2015) 
Fig. 10 STM images of (a) $\mathrm{Au}$ deposited on $2 \mathrm{ML} \mathrm{MgO(001)/}$ $\mathrm{Ag}(001)$ at $77 \mathrm{~K}$, and after subsequent annealing of the system to $343 \mathrm{~K}$ (b), $400 \mathrm{~K}$ (c) and $500 \mathrm{~K}(\mathbf{d})$. All images were taken at $77 \mathrm{~K}$. Scan area: a-c $25 \mathrm{~nm} \times 25 \mathrm{~nm}$; d $50 \mathrm{~nm} \times 50 \mathrm{~nm}$.

$U_{\text {bias }}=+(0.5-0.75)$ V. $I_{\mathrm{t}}=30$ pA. e Height profiles of representative islands/particles from the $400 \mathrm{~K}$ (dashed line) and $500 \mathrm{~K}$ (dotted line) annealed samples, highlighting the transition from $2 \mathrm{D}$ to $3 \mathrm{D}$ geometries (O’Brian et al. 2015)
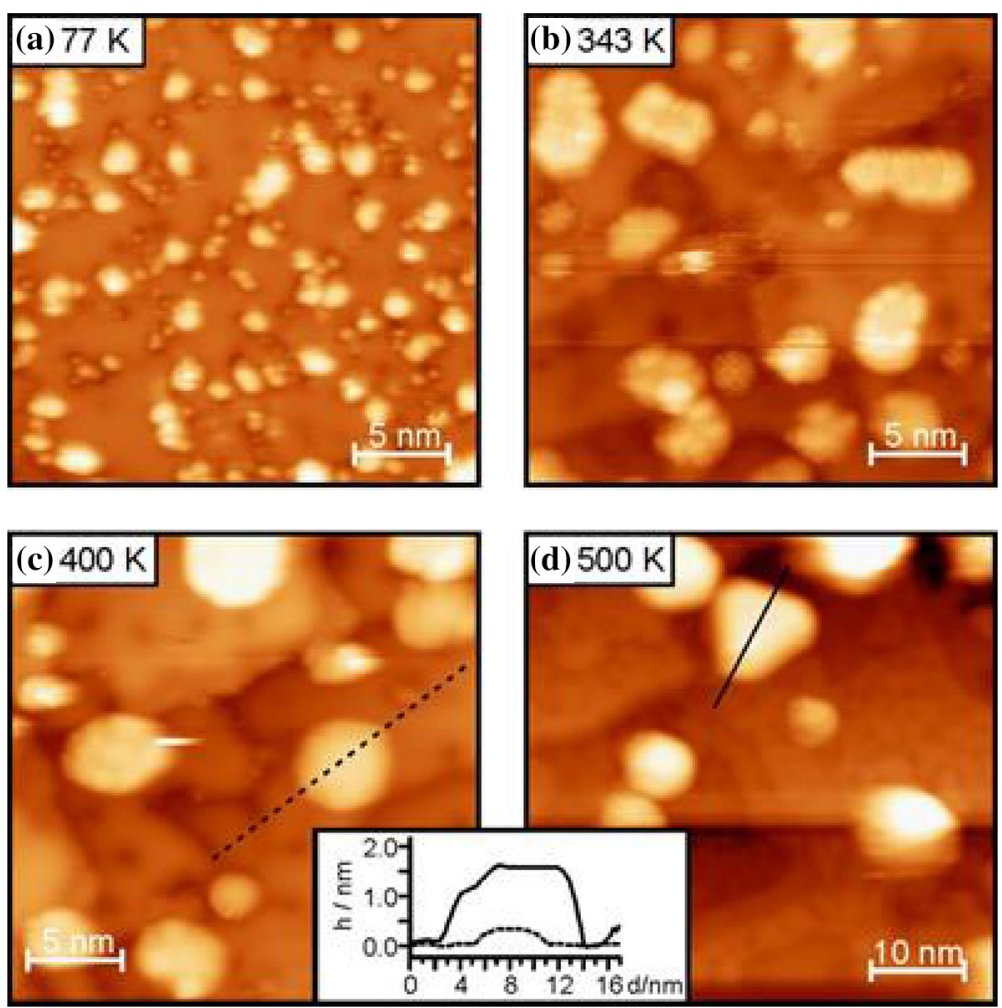

trace has been recorded after $\mathrm{Au}$ deposition, the formation of the raft-like particles, and exposure to $\mathrm{CO}_{2}$ at room temperature. The two extra bands are due to the formation of oxalate. Again, detailed isotopic labeling experiments confirm the formation of a $\mathrm{C}-\mathrm{C}$ bond in oxalate. Here we profit from the possibility to not only label the $\mathrm{CO}_{2}$ molecules adsorbed but also the possibility to label the oxide film by forming it using ${ }^{18} \mathrm{O}_{2}$ instead of ${ }^{16} \mathrm{O}_{2}$. This provides the unique way to differentiate the species formed from carbonate, which would need the involvement of oxygen from the substrate. For the subsequent spectra the temperature of the system has been systematically increased. Clearly, upon heating above $400 \mathrm{~K}$ prior to exposure to $\mathrm{CO}_{2}$, the oxalate bands attenuate $\left(\mathrm{O}^{\prime}\right.$ Brian et al. 2015), and by $600 \mathrm{~K}$ have practically disappeared. If this information is combined with the STM data shown also in Fig. 8, we may conclude that upon hearing above $500 \mathrm{~K}$ the particles tend to assume three-dimensional morphology, thus corroborating the idea, that those particles do not provide electrons to induce oxalate formation.

It should be noted, that thermal desorption studies on the system (Calaza et al. 2015) reveal that the formed oxalate may be desorbed as $\mathrm{CO}_{2}$ upon heating the adsorbate to a temperature larger than $340 \mathrm{~K}$. This is interesting, since there is also the possibility to form $\mathrm{CO}$ and carbonate $\left(\mathrm{CO}_{3}{ }^{2-}\right)$ upon heating, an observation made for oxalates formed in the presence of alkali co-adsorbates (Freund and
Roberts 1996; Solymosi 1991; Paul et al. 1988; Toomes and King 1996). It seems, that the low oxophilicity of $\mathrm{Au}$ prevents the formation of carbonate thus rendering the formation and decomposition of oxalate reversible in this system. As a final note in reference to the study of isophorone, presented above, we studied the influence of the negatively charged oxalate molecules onto the quantum well states of the Au nano-particles. The situation is quite different from the previous one, as the negative charge located at the rim represents, de facto, an increase in barrier height for the $\mathrm{Au}$ electrons, thus leading to the reverse effect on the spacing of the quantum well states as compared to isophorone. We have discussed this comparison in the literature (Fig. 9).

The example demonstrates, that basic knowledge may be used to unravel the details of a surface chemical reaction for those considerably more complex systems than metal single crystals, and provide evidence at the atomic level. One may now ask, whether this finding is only applicable to those rather esoteric thin film oxide systems or whether there is a way to transfer this to real powder catalyst systems? The answer is: possibly yes! We have previously demonstrated (Shao et al. 2011), that the flat raft-like $\mathrm{Au}$ structures may not only be formed at thin oxide films on top of a metal substrate, which provides the source for electrons, but rather also on thick oxide films, mimicking the bulk situation. Here, the electron source is provided 

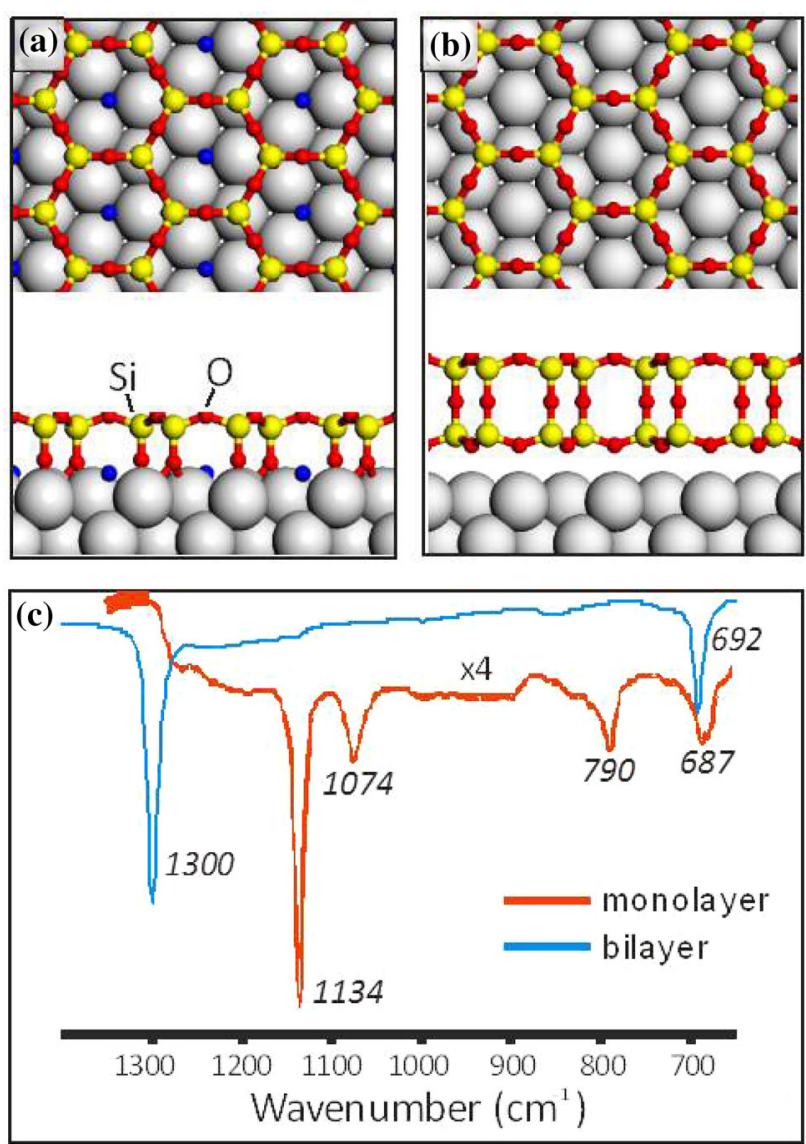

Fig. 11 Top and side views of the (a) monolayer and (b) bilayer silica films on $\mathrm{Ru}(0001)$. Below the IR spectra of the two films are depicted [adapted from Yang et al. (2012)]

through doping the oxide bulk with appropriate dopants with low electron releasing energetics. We provided as an example Mo dopants in a $\mathrm{CaO}$ (60 layers in thickness) where in the presence of the dopants raft-like Au nanoparticles form, while in the absence of dopants Au grows three-dimensional. It is envisioned that such systems could be used to transfer the above ideas to real catalytic systems. Experiments in this direction are under way.

\subsection{Silica films}

The group of the author has been studying silica films since about a decade in an attempt to provide a model substrate to study silica supported catalyst systems. One such system, envisioned is the Philips catalyst, where chromia is grafted to typically amorphous silica catalyzing the polymerization of ethene to poly-ethylene (McDaniel 1985, 2010). Our research in this direction had been inspired by work at the group of Adriano Zecchina in Torino (Groppo et al. 2005). We have not yet succeeded, but the example shown in this section demonstrates the way to tackle such a research problem and the kind of obstacles that have to be overcome. The challenge, before one could even consider grafting chromia to silica is to prepare an amorphous silica film, which allows for a characterization at the atomic level. In 2005 Weissenrieder et al. (Weissenrieder et al. 2005), in collaboration with Joachim Sauer's theoretical work, succeeded to image a monolayer silica film on $\operatorname{Mo}(112)$, after its preparation before by Schröder et al. (Schröder et al. 2000). In this film, the $\mathrm{SiO}_{4}$ tetraedra are linked into six-membered rings, with one of the $\mathrm{Si}-\mathrm{O}$ bonds directly connected to the metal substrate. This shown in Fig. 10 for a $\mathrm{Ru}(0001)$ surface where the same type of silica film may be prepared (Yang et al. 2012). The stoichiometry of this film is $\mathrm{SiO}_{2.5}$. However, on the latter metal surface, a bi-layer film may also be formed, as demonstrated in 2010 by D. Löffler et al. (2010), which has $\mathrm{SiO}_{2}$ stoichiometry, and is only bound to the metal substrate by dispersive forces. The network formed, as viewed from above (e.g., by STM) is identical to the monolayer, but the vibrational spectrum, as also shown in Fig. 10 reveals directly the differences in bonding. Therefore, in a combination of STM and IR spectroscopy the bi-layer film may uniquely be identified.

The Si-O-metal bond sows up in the monolayer at $1134 \mathrm{~cm}^{-1}$, while this band is missing in the bi-layer, and, instead, the $\mathrm{Si}-\mathrm{O}-\mathrm{Si}$ bond is observed at $1300 \mathrm{~cm}^{-1}$. While this is an ideal substrate to proceed in the direction indicated above, the film is ordered and we need an amorphous film. Note, that those films are prepared by depositing Si in an oxygen ambient at tested surface temperatures. Figure 11 shows STM images and LEED patterns of a film prepared at different deposition conditions. The films characterized on the left appears crystalline, with the STM revealing the hexagonal ring structure and a sharp spot LEED pattern, while the film on the right, shows a diffuse, ring-like LEED pattern and an irregular STM image, apparently showing rings of different size. The latter has later been identified in a detailed study by Lichtenstein et al. (2012a, b, c) and shown in Fig. 13 as a realization of the never before experimentally directly proven structure of amorphous silica, proposed by W.R. Zachariasen in 1932 (Zachariasen 1932) as the standard model for amorphous silica.

Figure 12 shows two images, taken with a setup, that allows for recording STM images and nc-AFM images at the same sample position. While STM is sensitive to the oxygen contrast, nc-AFM reveals the $\mathrm{Si}$ contrast. By superimposing the two images a clear picture of the amorphous silica structure is revealed, clearly identifying it as in line with the Zachariasen-structure. This film, therefore, is the ideal substrate to proceed with the task outlined at the top of this chapter. It is an amorphous silica layer of correct stoichiometry, whose structure we are able to 
Fig. 12 (Top) LEED patterns (at $60 \mathrm{eV}$ ) and STM images (bottom) of the bilayer silica films prepared by slow (on the left) and fast (on the right) cooling after the high temperature oxidation step in the film preparation [Tunneling parameters: $2 \mathrm{~V}, 0.1 \mathrm{nA}$ (left); $3.3 \mathrm{~V}, 0.1 \mathrm{nA}$ (right)] (Yang et al. 2012)
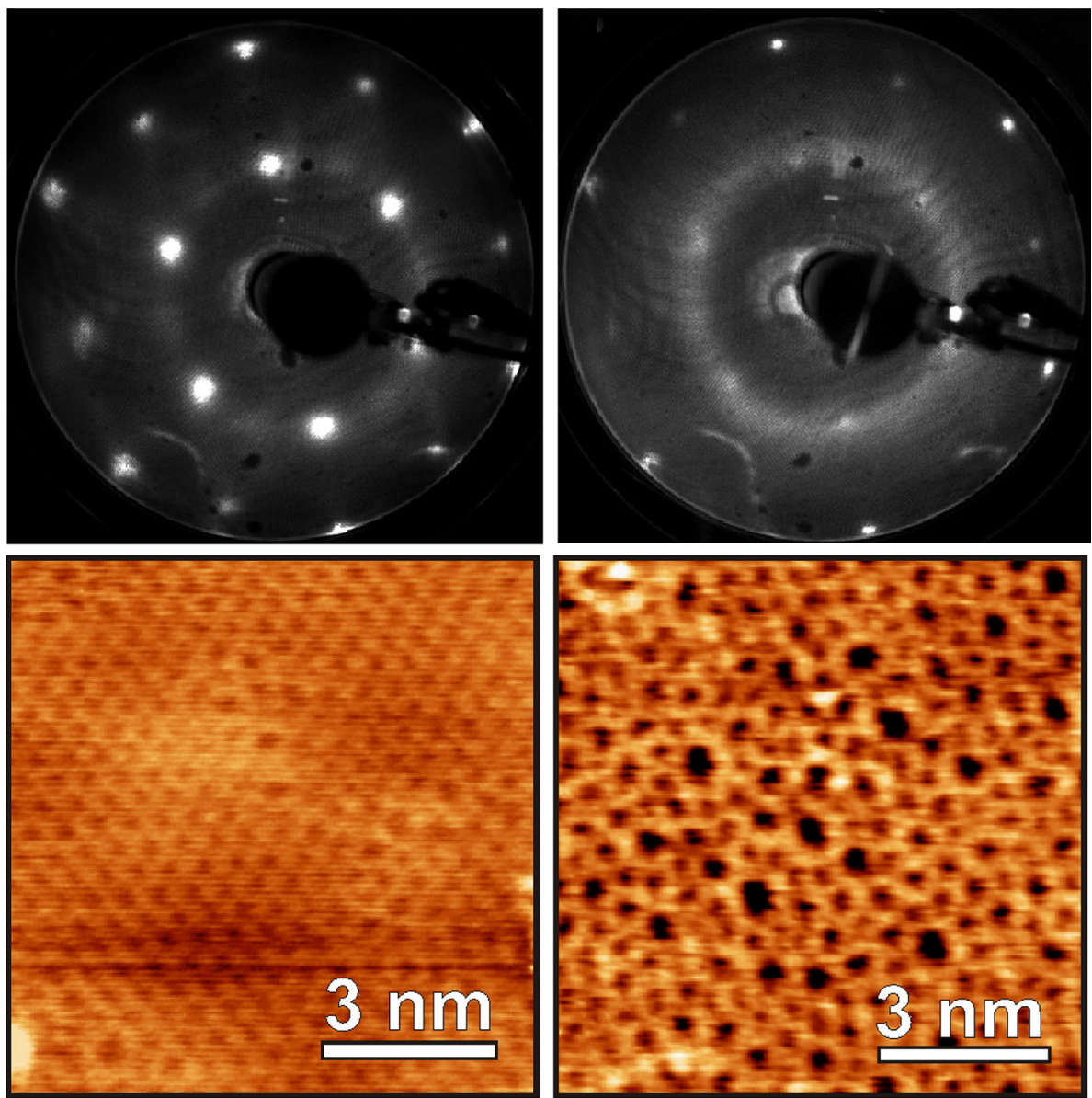
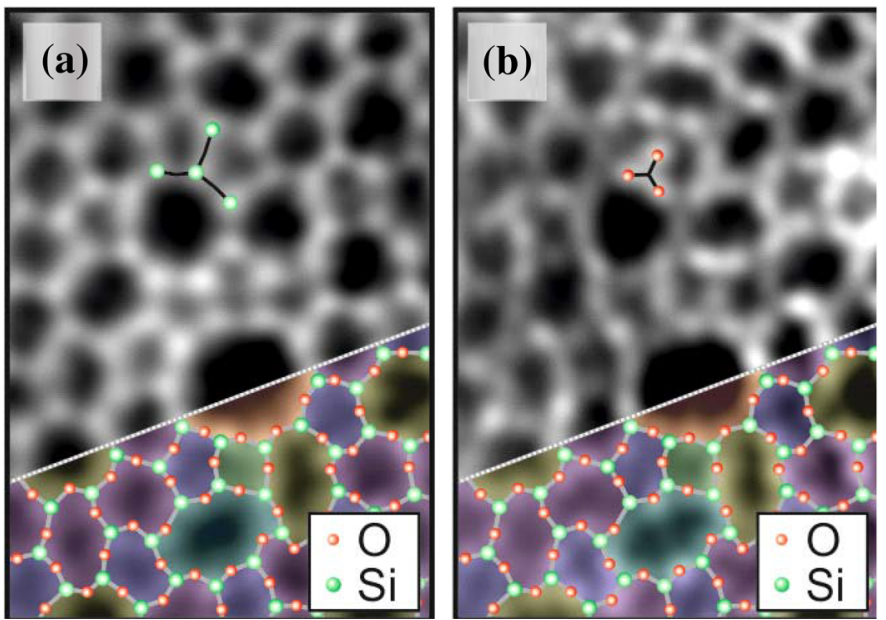

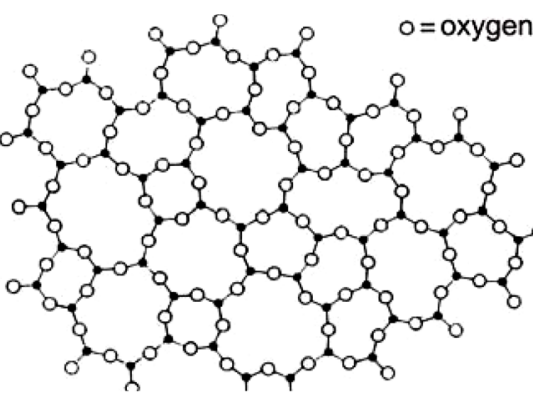

of the $\mathrm{O}$ atoms. An atomic model of the topmost layer of the silica film is superimposed onto the lower right corner of the images in a and b (green balls: $\mathrm{Si}$ atoms, red balls: $\mathrm{O}$ atoms). (Lichtenstein et al. 2012c) Zachariasen's scheme (Zachariasen 1932) of a random network (black dots: cations, white circles: anions) (color figure online) 


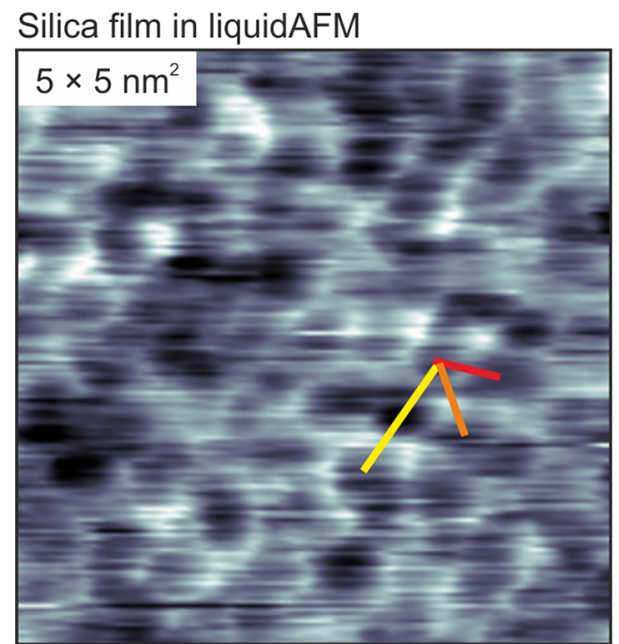

Fig. 14 a Liquid-AFM image of an amorphous silica bilayer film show ring resolution $\left(5 \times 5 \mathrm{~nm}^{2}, f=337 \mathrm{kHz}, A=0.2 \mathrm{~nm}\right.$, $k=26.4 \mathrm{~N} / \mathrm{m}, 400 \mathrm{mM}$ aqueous $\mathrm{NaCl}$ solution). b UHV-STM image of an amorphous silica bilayer film with atomic resolution of silicon atoms. $\left(5 \times 5 \mathrm{~nm}^{2}, I_{\mathrm{t}}=50 \backslash, V_{s}=2 \mathrm{~V}\right)$. The silicon atoms are

investigate at the atomic level. The next step towards the goal has to be the grafting of the $\mathrm{Cr}$ species to the surface. However, for this the surface needs to be hydroxylated. This turns out to be difficult as the film is extremely stable, even under water. We have recently been able to image the film under water using a commercial AFM system with near atomic resolution as shown in Fig. 13 (Burson et al. 2016). The ring structure, as compared with an image taken under UHV conditions is visible and there is no indication that this leads to any significant hydroxylation, except at surface defects.

The only way to significantly hydroxylate the film is by electron bombardment after exposing the silica film to an ice layer (Yu et al. 2016). We have recently demonstrated, that this leads to the formation of different hydroxyls, whose nature was unraveled using calculations performed by the Sauer group. The type of hydroxyl groups, formed upon electron bombardment, in-line with the experimental observations, are schematically shown in Fig. 14. The hydroxyl groups are formed with an orientation parallel as well as perpendicular to the surface. Only those with a dipole moment perpendicular to the surface may be identified with IR spectroscopy, while those parallel to the surface need characterization with off-specular electron energy loss spectroscopy. The latter study is underway (Richter et al. 2016). Once the information is available, we will proceed with grafting of the chromia species, and the model system is ready to investigate the reaction in question (Pan et al. 2016) (Fig. 15).

\section{Silica film in LT-UHV-STM}

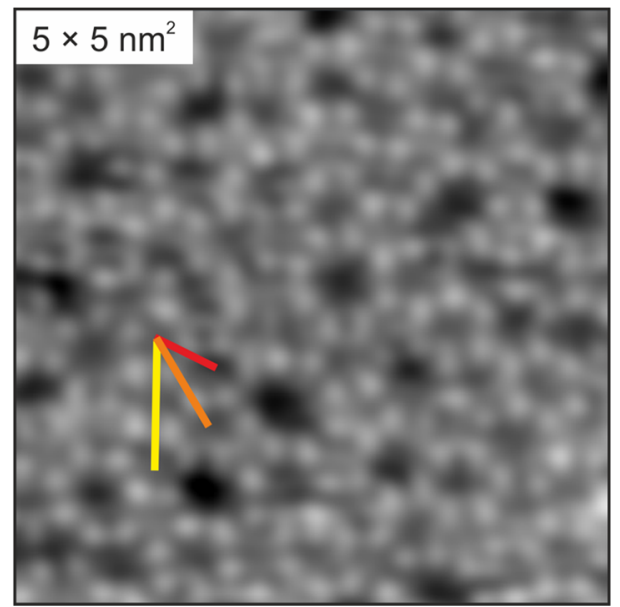

marked in green for several rings. Red, orange, and yellow measurement bars show examples of ring center-center distances for the first three families of ring neighbors identified in the amorphous silica bilayer. Several individual rings are marked in each image (Burson et al. 2016) (color figure online)

\section{Conclusion}

This study is intended to demonstrate the idea of model studies in catalysis and the effort necessary to establish model systems, that allow reaching conclusions connected with catalysis under realistic conditions. We have provided evidence, that models may provide detailed evidence at the atomic level, which at present cannot be attained with real catalysts, simply because the techniques available do not allow characterization at the detail necessary. The hope is that future developments enable more detailed studies also for real systems. Perhaps the newly developed-aberration corrected transmission electron microscopy will allow in the future to gain atomic level information at the surface of real powder catalyst systems as well. Clearly, there is much effort needed to finally be able to look at the working catalyst at atomic detail. Only this will finally allow us to deeply understand and design catalytic material. While heterogeneous catalysis is complex process and involves complex materials, similar situations are encountered in homogeneous and enzymatic catalysis. At first sight, one might argue that the structure of molecular complexes or even enzymes are explored by scattering and spectroscopic techniques, but if one is honest, the presence of solvents and the non-crystalline environment in solution still present huge challenges to establish in situ structure function-relations for those branches of catalysis as well. In this sense the community should strive for a unifying concept in catalysis. 


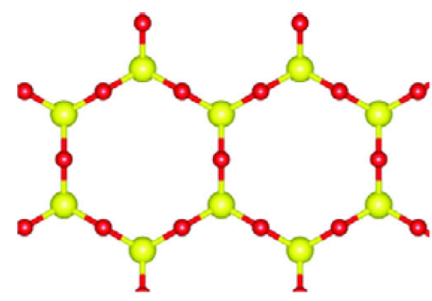

(a) $\mathrm{SiO}_{2}$ bilayer, top

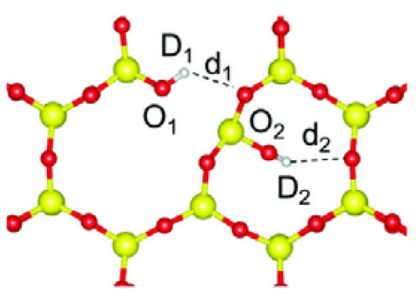

(c) Structure la, top

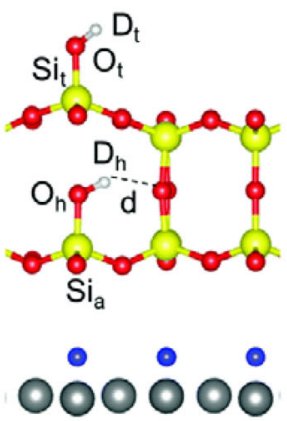

(e) Structure Ib

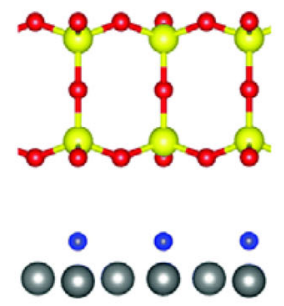

(b) side view

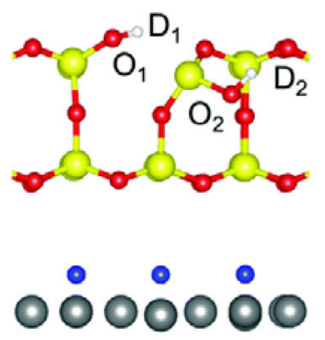

(d) side view

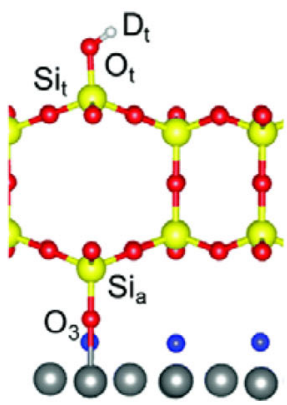

(f) Structure II
Fig. 15 Top (a) and side (b) views of the pristine silica bilayer. Top (c) and side (d) views of the hydroxylation structure Ia. e Side view of the hydroxylated structure Ib. f Side view of the structure that forms a $\mathrm{Si}-\mathrm{O}-\mathrm{Ru}$ bridge to the $\mathrm{Ru}$ surface. $\mathrm{Si}, \mathrm{O}$ and $\mathrm{Ru}$ atoms are shown in yellow, red, and gray, respectively. The $\mathrm{O}$ (or $\mathrm{H}$ for a $\mathrm{H}$-precovered model,) atoms only adsorbed on the $\mathrm{Ru}(0001)$ surface are shown in blue (Yu et al. 2016) (color figure online)

Acknowledgments Open access funding provided by Max Planck Society. The author thanks all his collaborators, resent and previous, who have contributed to the work reviewed here. Their names are mentioned in the references. He also thanks Hannu Häkkinen, Gianfranco Pacchioni, and Joachim Sauer for many fruitful discussions and collaboration over many years. Financial support by the German Science Foundation through SFB 1109 and the Cluster of Excellence "UniCat", as well as by the German Israeli Foundation (GIF 1236) and the Fonds der Chemischen Industrie is gratefully acknowledged.

Open Access This article is distributed under the terms of the Creative Commons Attribution 4.0 International License (http://crea tivecommons.org/licenses/by/4.0/), which permits unrestricted use, distribution, and reproduction in any medium, provided you give appropriate credit to the original author(s) and the source, provide a link to the Creative Commons license, and indicate if changes were made.

\section{References}

Bardi U, Atrei A, Rovida G (1992) Initial stages of oxidation of the $\mathrm{Ni}_{3} \mathrm{Al}$ alloy: structure and composition of the aluminum oxide overlayer studied by XPS, LEIS and LEED. Surf Sci 268(1-3):87-97. doi:10.1016/0039-6028(92)90952-3

Bäumer M, Freund H-J (1999) Metal deposits on well-ordered oxide films. Prog Surf Sci 61(7-8):127-198. doi:10.1016/s00796816(99)00012-x

Bäumer M, Libuda J, Freund H-J (1997) Metal deposits on thin well ordered oxide films: morphology, adsorption and reactivity. Chemisorption and reactivity on supported clusters and thin films, vol 331. Kluwer Academic Publishers, Dordrecht

Becker C, Kandler J, Raaf H, Linke R, Pelster T, Dräger M, Tanemura M, Wandelt K (1998) Oxygen adsorption and oxide formation on $\mathrm{Ni}_{3} \mathrm{Al}$ (111). J Vac Sci Technol A 16(3):1000-1005. doi:10.1116/1.581221

Belton DN, Schmieg SJ (1988a) Interaction of $\left[\mathrm{Rh}(\mathrm{CO})_{2} \mathrm{Cl}\right]_{2}$ with $\mathrm{O}_{2}$ oxidized $\mathrm{Al}(100)$ : effect of $\mathrm{Al}_{2} \mathrm{O}_{3}$ preparation on $\left[\mathrm{Rh}(\mathrm{CO})_{2} \mathrm{Cl}\right]_{2}$ decomposition. Surf Sci 199(3):518-536. doi:10.1016/00396028(88)90919-3

Belton DN, Schmieg SJ (1988b) Effect of Rh particle size on CO desorption from Rh/alumina model catalysts. Surf Sci 202(1-2):238-254. doi:10.1016/0039-6028(88)90071-4

Böhme DK, Schwarz H (2005) Gas-phase catalysis by atomic and cluster metal ions: the ultimate single-site catalysts. Angew Chem Int Ed 44(16):2336-2354. doi:10.1002/anie.200461698

Campbell CT (1997) Ultrathin metal films and particles on oxide surfaces: structural, electronic and chemisorption properties. Surf Sci Rep 27:1-111

Chen JG, Crowell JE, Yates JT Jr (1987) The metal-metal oxide interface: a study of thermally-activated diffusion at the $\mathrm{Ni} /$ $\mathrm{Al}_{2} \mathrm{O}_{3}$ interface using electron spectroscopies. Surf Sci 185(3):373-393. doi:10.1016/S0039-6028(87)80165-6

Chen JG, Colaianni ML, Weinberg WH, Yates JT Jr (1992) The Cu/ $\mathrm{Al}_{2} \mathrm{O}_{3} / \mathrm{Al}(111)$ interface: initial film growth and thermally induced diffusion of copper into the bulk. Surf Sci 279(3):223-232. doi:10.1016/0039-6028(92)90548-K

Diebold U, Pan J-M, Madey TE (1995) Ultrathin metal film growth on $\mathrm{TiO}_{2}(110)$ : an overview. Surf Sci 331-333:845

Ertl G (2007) Reactions at surfaces: from atoms to complexity. http:// www.nobelprize.org/nobel_prizes/chemistry/laureates/2007/ ertl_lecture.pdf. Accessed 8 Dec 2007

Ertl G (2008) Reactions at surfaces: from atoms to complexity (nobel lecture). Angew Chem Int Ed 47(19):3524-3535. doi:10.1002/ anie. 200800480

Ertl G, Freund HJ (1999) Catalysis and surface science. Phys Today 52(1):32-38. doi:10.1063/1.882569

Ertl G, Knözinger H, Weitkamp J (1997) Handbook of heterogeneous catalysis. VCH, Weinheim

Freund H-J (1995) Metal oxide surfaces-electronic structure and molecular adsorption. Phys Status Solidi B 192(2):407-440

Freund HJ (1997) Adsorption of gases on complex solid surfaces. Angew Chem Int Ed 36(5):452-475. doi:10.1002/anie. 199704521

Freund HJ (2010) Model studies in heterogeneous catalysis. Chem Eur J 16(31):9384-9397. doi:10.1002/chem.201001724

Freund H-J, Pacchioni G (2008) Oxide ultra-thin films on metals: new materials for the design of supported metal catalysts. Chem Soc Rev 37(10):2224-2242. doi:10.1039/b718768h 
Freund H-J, Nilius N, Risse T, Schauermann S, Schmidt T (2011) Innovative measurement techniques in surface science. ChemPhysChem 12(1):79-87. doi:10.1002/cphc.201000812

Freund HJ, Nilius N, Risse T, Schauermann S (2014) A fresh look at an old nano-technology: catalysis. Phys Chem Chem Phys 16(18):8148-8167. doi:10.1039/C3CP55231D

Goodman DW (1994) Catalysis: from single crystals to the "real world". Surf Sci 299-300:837-848. doi:10.1016/00396028(94)90701-3

Goodman DW (1995) Model catalysts-from extended single crystals to supported particles. Surf Rev Lett 2:9-24

Heiz U, Vanolli F, Trento L, Schneider WD (1997) Chemical reactivity of size-selected supported clusters: an experimental setup. Rev Sci Instrum 68:1986

Jaeger RM, Kuhlenbeck H, Freund HJ, Wuttig M, Hoffmann W, Franchy R, Ibach H (1991) Formation of a well-ordered aluminium oxide overlayer by oxidation of NiA(110). Surf Sci 259(3):235-252. doi:10.1016/0039-6028(91)90555-7

Libuda J, Winkelmann F, Bäumer M, Freund H-J, Bertrams T, Neddermeyer H, Müller K (1994) Structure and defects of an ordered alumina film on NiAl(110). Surf Sci 318:61-73

Marin G, Yablonsky GS (2011) Kinetics of chemical reactions. Wiley-VCH Verlag GmbH \& Co. KGaA, Weinheim

Ostwald W (1923) Über Katalyse. Akademische Verlagsgesellschaft, Leipzig

Pacchioni G, Freund H (2012) Electron transfer at oxide surfaces. The $\mathrm{MgO}$ paradigm: from defects to ultrathin films. Chem Rev 113(6):4035-4072. doi:10.1021/cr3002017

Persaud R, Madey TE (1997) Chapter 11 Growth, structure and reactivity of ultrathin metal films on $\mathrm{TiO}_{2}$ surfaces. In: King DA, Woodruff DP (eds) The chemical physics of solid surfaces, vol Volume 8. Elsevier, pp. 407-447. doi:http://dx.doi.org/10.1016/ S1571-0785(97)80014-4

Rochet F, Rigo S, Froment M, d'Anterroches C, Maillot C, Roulet H, Dufour G (1986) The thermal oxidation of silicon the special case of the growth of very thin films. Adv Phys 35(3):237-274. doi: $10.1080 / 00018738600101891$

Sauer J, Freund H-J (2015) Models in catalysis. Catal Lett 145(1):109-125. doi:10.1007/s10562-014-1387-1

Pantelides ST et al. (1978) The Physics of $\mathrm{SiO}_{2}$ and its Interfaces. In: Proceedings of the International Topical Conference on the Physics of $\mathrm{SiO}_{2}$ and Its Interfaces. IBM Thomas J. Waston Research Center, Yorktown Heights. Pergamon Press, New York

Bäumer M, Cappus D, Kuhlenbeck H, Freund HJ, Wilhelmi G, Brodde A, Neddermeye H (1991) The structure of thin NiO(100) films grown on $\mathrm{Ni}(100)$ as determined by low-energy-electron diffraction and scanning tunneling microscopy. Surf Sci 253(1-3): 116

Burson KM, Gura L, Kell B, Büchner C, Lewandowski AL, Freund H-J (2016) Resolving amorphous solid-liquid interfaces by atomic force microscopy. App Phys Lett 108:201602. doi:10. $1063 / 1.4949556$

Calaza F, Stiehler C, Fujimori Y, Sterrer M, Beeg S, Ruiz-Oses M, Nilius N, Heyde M, Parviainen T, Honkala K, Häkkinen H, Freund H-J (2015) Carbon dioxide activation and reaction induced by electron transfer at an oxide-metal interface. Angew Chem Int Ed 54(42):12484-12487. doi:10.1002/anie.201501420

Chen M, Goodman DW (2008) Catalytically active gold on ordered titania supports. Chem Soc Rev 37(9):1860-1870

Compton RN, Reinhardt PW, Cooper CD (1975) Collisional ionization of $\mathrm{Na}, \mathrm{K}$, and $\mathrm{Cs}$ by $\mathrm{CO}_{2}, \mathrm{COS}$, and $\mathrm{CS}_{2}$ : molecular electron affinities. J Chem Phys 63(9):3821-3827. doi:10.1063/1.431875

Freund H-J, Roberts MW (1996) Surface chemistry of carbon dioxide. Surf Sci Rep 25(8):225-273

Goodman DW (1996) Chemical and spectroscopic studies of metal oxide surfaces. J Vac Sci Technol A 14:1526
Groppo E, Lamberti C, Bordiga S, Spoto G, Zecchina A (2005) The structure of active centers and the ethylene polymerization mechanism on the $\mathrm{Cr} / \mathrm{SiO} 2$ catalyst: a frontier for the characterization methods. Chem Rev 105(1):115-184. doi:10.1021/ cr040083s

Haruta M, Tsubota S, Kobayashi T, Kageyama H, Genet MJ, Delmon B (1993) Low-temperature oxidation of $\mathrm{CO}$ over gold supported on $\mathrm{TiO}_{2}, \alpha-\mathrm{Fe}_{2} \mathrm{O}_{3}$, and $\mathrm{Co}_{3} \mathrm{O}_{4}$. J Catal 144(1):175-192. doi:10. 1006/jcat.1993.1322

Herzing AA, Kiely CJ, Carley AF, Landon P, Hutchings GJ (2008) Identification of active gold nanoclusters on iron oxide supports for CO oxidation. Science 321:1331-1335. doi:10.1126/science. 1159639

Kuhlenbeck H, Xu C, Dillmann B, Haßel M, Adam B, Ehrlich D, Wohlrab S, Freund H-J, Ditzinger UA, Neddermeyer H, Neuber M, Neumann M (1992) Adsorption and reaction on oxide surfaces: $\mathrm{CO}$ and $\mathrm{CO}_{2}$ on $\mathrm{Cr}_{2} \mathrm{O}_{3}(111)$. Ber Bunsenges Phys Chem 96:15

Langan JD, Hansma PK (1975) Can the concentration of surface species be measured with inelastic electron tunneling? Surf Sci 52(1):211-216. doi:10.1016/0039-6028(75)90020-5

Li J, Li X, Zhai H-J, Wang L-S (2003) $\mathrm{Au}_{20}$ : a tetrahedral cluster. Science 299:864-867. doi:10.1126/science.1079879

Lichtenstein L, Büchner C, Yang B, Shaikhutdinov S, Heyde M, Sierka M, Włodarczyk R, Sauer J, Freund H-J (2012a) The atomic structure of a metal-supported vitreous thin silica film. Angew Chem Int Ed 51(2):404-407. doi:10.1002/anie. 201107097

Lichtenstein L, Heyde M, Freund H-J (2012b) Crystalline-vitreous interface in two dimensional silica. Phys Rev Lett 109(10): 106101

Lichtenstein L, Heyde M, Freund H-J (2012c) Atomic arrangement in two-dimensional silica: from crystalline to vitreous structures. J Phys Chem C 116:20426-20432. doi:10.1021/jp3062866

Lin X, Nilius N, Freund HJ, Walter M, Frondelius P, Honkala K, Häkkinen H (2009) Quantum well states in two-dimensional gold clusters on $\mathrm{MgO}$ thin films. Phys Rev Lett 102(20):206801

Lin X, Nilius N, Sterrer M, Koskinen P, Haekkinen H, Freund H-J (2010a) Characterizing low-coordinated atoms at the periphery of $\mathrm{MgO}$-supported $\mathrm{Au}$ islands using scanning tunneling microscopy and electronic structure calculations. Phys Rev B 81(15): 153406

Lin X, Yang B, Benia HM, Myrach P, Yulikov M, Aumer A, Brown M, Sterrer M, Bondarchuk O, Kieseritzky E, Rocker J, Risse T, Gao H, Nilius N, Freund HJ (2010b) Charge-mediated adsorption behavior of $\mathrm{CO}$ on $\mathrm{MgO}$-supported Au clusters. J Am Chem Soc 132(22):7745-7749

Löffler D, Uhlrich JJ, Baron M, Yang B, Yu X, Lichtenstein L, Heinke L, Büchner C, Heyde M, Shaikhutdinov S, Freund H-J, Włodarczyk R, Sierka M, Sauer J (2010) Growth and structure of crystalline silica sheet on $\operatorname{Ru}(0001)$. Phys Rev Lett 105(14): 146104

McDaniel MP (1985) Supported chromium catalysts for ethylene polymerization. In: D.D. Eley HP, Paul BW (eds) Adv. Catal., vol Volume 33. Academic Press, pp 47-98. doi:http://dx.doi.org/ 10.1016/S0360-0564(08)60258-8

McDaniel MP (2010) Chapter 3-a review of the Phillips supported chromium catalyst and its commercial use for ethylene polymerization. In: Bruce CG, Helmut K (eds) Adv. Catal., vol Volume 53. Academic Press, pp 123-606. doi:http://dx.doi.org/ 10.1016/S0360-0564(10)53003-7

O'Brian CP, Dostert K-H, Hollerer M, Stiehler C, Calaza F, Schauermann S, Shaikhutdinov S, Sterrer M, Freund H-J (2015) Supports and modified nano-particles in designing model catalysts. Faraday Discuss. doi:10.1039/C5FD00143A 
Pacansky J, Wahlgren U, Bagus PS (1975) SCF ab initio ground state energy surfaces for $\mathrm{CO}_{2}$ and $\mathrm{CO}_{2}{ }^{-}$. J Chem Phys 62(7):2740-2744. doi:10.1063/1.430807

Pan Q, Shaikhutdinov S, Freund H-J (2016) (to be submitted)

Paul J, Hoffmann FM, Robbins LL (1988) Carbon monoxide and carbon dioxide decomposition on bulk polycrystalline alkali metals. J Phys Chem 92:6967

Quitevis EL, Herschbach DR (1989) Electron attachment to carbon dioxide clusters by collisional charge transfer. J Phys Chem 93(3):1136-1139. doi:10.1021/j100340a023

Rashkeev SN, Lupini AR, Overbury SH, Pennycook SJ, Pantelides ST (2007) Role of the nanoscale in catalytic CO oxidation by supported Au and Pt nanostructures. Phys Rev B 76(3):035438

Ricci D, Bongiorno A, Pacchioni G, Landman U (2006) Bonding trends and dimensionality crossover of gold nanoclusters on metal-supported $\mathrm{MgO}$ thin films. Phys Rev Lett 97(3):036106

Richter N, Risse T, Pal J, Shaikhutdinov S, Freund H-J (2016) (to be submitted)

Rohr F, Bäumer M, Freund HJ, Mejias JA, Staemmler V, Müller S, Hammer L, Heinz K (1997a) Strong relaxations at the $\mathrm{Cr}_{2} \mathrm{O}_{3}(0001)$ surface as determined via low-energy electron diffraction and molecular dynamics simulations. Surf Sci 372(1-3):L291-L297. doi:10.1016/s0039-6028(96)01255-1

Rohr R, Bäumer M, Freund HJ, Mejias JA, Staemmler V, Müller S, Hammer L, Heinz K (1997b) Erratum to "Strong relaxations a the $\mathrm{Cr}_{2} \mathrm{O}_{3}(0001)$ surface as determined via low-energy electron diffraction and molecular dynamics simulations" [vol 372, p 291. 1997]. Surf Sci 389(1-3):391. doi:10.1016/s00396028(97)00518-9

Rossi AR, Jordan KD (1979) Comment on the structure and stability of $\left(\mathrm{CO}_{2}\right)_{-2}$. J Chem Phys 70(9):4422-4424. doi:10.1063/1. 438018

Schröder T, Adelt M, Richter B, Naschitzki M, Bäumer M, Freund $\mathrm{H}-\mathrm{J}$ (2000) Epitaxial growth of $\mathrm{SiO}_{2}$ on $\mathrm{Mo}(112)$. Surf Rev Lett $7: 7-14$

Seiferth O, Wolter K, Dillmann B, Klivenyi G, Freund HJ, Scarano D, Zecchina A (1999) IR investigations of $\mathrm{CO}_{2}$ adsorption on chromia surfaces: $\mathrm{Cr}_{2} \mathrm{O}_{3}(0001) / \mathrm{Cr}(110)$ versus polycrystalline $\alpha-\mathrm{Cr}_{2} \mathrm{O}_{3}$. Surf Sci 421(1-2):176-190. doi:10.1016/s00396028(98)00857-7

Shao X, Prada S, Giordano L, Pacchioni G, Nilius N, Freund H-J (2011) Tailoring the shape of metal ad-particles by doping the oxide support. Angew Chem Int Ed 50(48):11525-11527. doi:10.1002/anie.201105355
Solymosi $\mathrm{F}$ (1991) The bonding, structure and reactions of $\mathrm{CO}_{2}$ adsorbed on clean and promoted metal surfaces. J Mol Catal 65(3):337-358. doi:10.1016/0304-5102(91)85070-I

Stamatovic A, Stephan K, Märk TD (1985) Electron attachment and electron ionization of van der Waals clusters of carbon dioxide. Int J Mass Spectrom 63(1):37-47. doi:10.1016/01681176(85)87039-7

Sterrer M, Heyde M, Novicki M, Nilius N, Risse T, Rust HP, Pacchioni G, Freund HJ (2006) Identification of color centers on $\mathrm{MgO}(001)$ thin films with scanning tunneling microscopy. J Phys Chem B 110(1):46-49. doi:10.1021/jp056306f

Sterrer M, Risse T, Heyde M, Rust H-P, Freund H-J (2007) Crossover from three-dimensional to two-dimensional geometries of $\mathrm{Au}$ nanostructures on Thin $\mathrm{MgO}(001)$ films: a confirmation of theoretical predictions. Phys Rev Lett 98(20):206103

Stiehler C, Calaza F, Schneider W-D, Nilius N, Freund H-J (2015) Molecular adsorption changes the quantum structure of oxidesupported gold nanoparticles: chemisorption versus physisorption. Phys Rev Lett 115(3):036804

Stiehler C, Calaza F, Sterrer M, Schneider W-D, Nilius N, Freund H-J (2016) (to be published)

Stipe BC, Rezaei MA, Ho W (1998) Single-molecule vibrational spectroscopy and microscopy. Science 280(5370):1732-1735. doi:10.1126/science.280.5370.1732

Toomes RL, King DA (1996) Coadsorption and surface compound formation in the interaction of $\mathrm{CO}_{2}$ with $\mathrm{K}$ on $\mathrm{Co}\{1010\}$. Surf Sci 349(1):65-80. doi:10.1016/0039-6028(95)01052-1

Weissenrieder J, Kaya S, Lu J-L, Gao H-J, Shaikhutdinov S, Freund H-J, Sierka M, Todorova TK, Sauer J (2005) Atomic structure of a thin silica film on a $\mathrm{Mo}(112)$ substrate: a two-dimensional network of $\mathrm{SiO}_{4}$ tetrahedra. Phys Rev Lett 95(7):076103

Yang B, Kaden WE, Yu X, Boscoboinik JA, Martynova Y, Lichtenstein L, Heyde M, Sterrer M, Wlodarczyk R, Sierka M, Sauer J, Shaikhutdinov S, Freund H-J (2012) Thin silica films on $\mathrm{Ru}(0001)$ : monolayer, bilayer and three-dimensional networks of $\left[\mathrm{SiO}_{4}\right]$ tetrahedra. Phys Chem Chem Phys 14(32):11344-11351

Yu X, Emmez E, Pan Q, Yang B, Pomp S, Kaden WE, Sterrer M, Shaikhutdinov S, Freund H-J, Goikoetxea I, Wlodarczyk R, Sauer J (2016) Electron stimulated hydroxylation of a metal supported silicate film. Phys Chem Chem Phys 18(5):3755-3764. doi:10.1039/C5CP06852E

Zachariasen WH (1932) The atomic arrangement in glass. J Am Chem Soc 54(10):3841-3851. doi:10.1021/ja01349a006 